JOURNAL REVIEW

\section{"It would be weird to have that on Facebook": young people's use of social media and the risk of sharing sexual health information}

Byron P, Albury K, Evers C. Reprod Health Matters 2013;21:35-44

We know that the majority of teenagers with regular Internet access have Facebook accounts. A 2012 study of teenagers in the USA found that $94 \%$ of those aged 12-17 years were signed up to the Facebook website. ${ }^{1}$ What this paper attempts to unpick are the complex ways in which young people actually use the site, to assess the potential of delivering sexual health promotion messages online. Small focus groups were held to ascertain young people's experiences of using Facebook and how, if at all, sexual health messages might be promoted to their peers in this context.

That young people's online and offline interactions are intertwined is an important point, and the young participants relate their concerns about sharing or 'liking' personal information online for fear of inviting 'drama' or bullying. The Pew Research Center report entitled 'Teens, Social Media, and Privacy' demonstrates that young users of Facebook undertake "online reputation management" by editing or restricting information that may expose them in this way. ${ }^{1}$ Considering 70\% reported being Facebook 'friends' with their parents, this is unsurprising!

The conclusions reached in this paper (that social media work attempting to target young people should be youth-led, and that 'funny videos' may be one way to encourage the sharing of sexual health information online) provide professionals with a useful starting point from which to tackle social media engagement. [NB: In the UK, the Centre for HIV and Sexual Health in Sheffield has had success with this format, gaining over 15000 views and three awards for their video raising awareness about HIV transmission. ${ }^{2}$ ]

The complexity of the messages received from these focus groups (Facebook is "the source for everything", yet "it's not for that") reiterate the importance of consulting with the specific demographic professionals are seeking to reach. What applies to teenagers in Australia might not apply to teenagers in the UK. What worked in 2011 may no longer be relevant in 2013. Social media interventions need to be up to date and youth-led if they have any chance of reaching their desired audience.

Although Facebook is currently the most popular social networking site for young people, the requirement to identify oneself using a real name may be a significant barrier to consuming and sharing information about sexual health. Sites that provide greater opportunity for anonymity (such as Tumblr and Twitter) are proving increasingly popular with young people, and it would be useful to see an exploration of the impact this might have on expanding young people's willingness to engage with sexual health information online.

Reviewed by Laura Hurley

Senior Project Worker, Brook, London, UK; laura.hurley@brook.org.uk

Competing interests None.

Provenance and peer review

Commissioned; internally peer reviewed.

J Fam Plann Reprod Health Care 2013;39:280.

doi:10.1136/jfprhc-2013-100739

\section{REFERENCES}

1 Pew Internet. Teens, Social Media, and Privacy. http://www.pewinternet.org/Reports/ 2013/Teens-Social-Media-And-Privacy/ Main-Report/Part-1.aspx [accessed 28 July 2013].

2 Positively Sheffield. The HIV Hop. http:// www.positivelysheffield.co.uk/the-hiv-hop/ [accessed 28 July 2013]. 